\title{
Identification of Six Novel SOD1 Gene Mutations in Familial Amyotrophic Lateral Sclerosis
}

\author{
Y. Boukaftane, J. Khoris, B. Moulard, F. Salachas, V. Meininger, A. Malafosse, \\ W. Camu and G.A. Rouleau
}

\begin{abstract}
Amyotrophic lateral sclerosis (ALS) is a neurodegenerative disease characterized by the premature death of motor neurons. In approximately $10 \%$ of the cases the disease is inherited as autosomal dominant trait (FALS). It has been found that mutations in the $\mathrm{Cu} / \mathrm{Zn}$ superoxide dismutase gene (SOD1) are responsible for approximately $15 \%$ of FALS kindreds. We screened affected individuals from 70 unrelated FALS kindreds and identified 10 mutations, 6 of which are novel. Surprisingly, we have found a mutation in exon 3 , which includes most of the active site loop and $\mathrm{Zn}^{2+}$ binding sites, a region where no previous SOD1 mutations have been found. Our data increase the number of different SOD1 mutations causing FALS to 55, a significant fraction of the 154 amino acids of this relatively small protein.
\end{abstract}

RÉSUMÉ: Identification de six nouvelles mutations dans le gène SOD1 de patients atteints de la Sclérose Laterale Amyotrophique. La Sclérose Laterale Amyotrophique (SLA) est une maladie neurodégénérative caractérisée par la mort prématurée des motoneurones. Dans 10\% des cas, la SLA est hérédiataire et caractérisée par une transmission autosomique dominante (SLAF). Il a été prouvé que des mutations dans le gène codant pour la $\mathrm{Cu} / \mathrm{Zn}$ superoxyde dismutase (SOD1) sont responsables de $15 \%$ des cas de SLAF. L'analyse des régions condantes du gène SOD1 de 70 patients nonapparentés atteints de SLAF nous a permis de découvrir 10 mutations dont six sont nouvelles. Fait inatendu, nous avons trouvé la première mutation dans l'exon 3 qui code pour la majeure partie du site actif et des sites de fixation du $\mathrm{Zn}^{2+}$. De plus, nous avons identifé une deuxième mutation recessive. Cette étude porte le nombre de mutations SOD1 différentes à 55 impliquant 37 codons, une fraction significative de cette protéine relativement petite constituée de 154 acides aminés.

Can. J. Neurol. Sci. 1998; 25: 192-196

Amyotrophic lateral sclerosis (ALS) is a fatal neurological disorder characterized by progressive degeneration of large motor neurons in the motor cortex, brainstem and spinal cord. The mean age at onset of the disease is 45 years with a mean survival of 3 years. ${ }^{1,2}$ ALS occurs in two clinically indistinguishable forms, sporadic (SALS; 90\%) and familial (FALS; 10\%). FALS is usually inherited as autosomal dominant trait ${ }^{3}$ though a few kindreds show autosomal recessive inheritance. ${ }^{4,5}$

Approximately $15 \%$ of all dominant FALS are caused by a defect in the cytosolic $\mathrm{Cu} / \mathrm{Zn}$ superoxide dismutase gene (SOD1) localized to human chromosome $2 \mathrm{lq} 22.1{ }^{6,7}$ To date forty-five different missense mutations affecting 34 codons, one nonsense mutation, one deletion mutation causing a frameshift and two intronic mutation in intron 4 have been described in the SOD1 gene. ${ }^{8}$ All the SODI mutations are dominant except for the Asp90Ala mutation which is thought to be recessive. ${ }^{5.9}$ In order to study the effect of these mutations and to gain insight into the mechanisms leading to motor neuron degeneration animal models of FALS have been generated using mutant SOD1 transgenes. ${ }^{10,12}$

We have screened genomic DNA from 70 unrelated patients for mutations in the SOD1 gene by PCR-SSCP. Here, we report six new and unpublished SOD1 gene mutations found in six unrelated patients.

\section{Patients and Methods}

\section{Patients}

Blood was collected from 70 unrelated patients with FALS. These FALS kindreds were of Canadian and French origins. The El

From the Centre for Research in Neuroscience, McGill University, and the Montreal General Hospital Research Institute, Montreal, Canada, (Y.B., J.K., G.A.R.);

Laboratoire de Médecine Expérimentale, Institut de Biologie, Montpelier, France (B.M.); Service de Neurologie, division Mazarin, Hôpital de la Salpétrière, Paris, France (F.S., V.M.); Division de Neuropsychiatrie, Hôpital Belle-ldée, Genève, Suisse (A.M.); Département de physiopathologie Neuromusculaire, Institut de Biologie, Montpelier, France (W.C.).

RECEIVED JUNE 4, 1998. ACCEPTED IN FinAL FORM JUNE 5, 1998.

Reprint requests to: G.A. Rouleau: $\operatorname{Rm}$ L7 224. Department of Neurology, Montreal General Hospital, 1650 Cedar Avenue, Montreal, Quebec, Canada, H3G IA4 
Escorial diagnostic criteria were used. ${ }^{13}$ Genomic DNA was prepared from blood using standard procedures.

\section{Primer design, SSCP analysis and direct sequencing}

To improve the PCR amplification of SOD1 gene exons for SSCP screening, we designed new intronic primers for exons 1 to 3 (Table 1). PCR amplification of exons 4 and 5 was performed using primers as previously described. ${ }^{14}$

The $50 \mu \mathrm{l}$ amplification reaction contained $100 \mathrm{ng}$ of genomic DNA, 1X PCR buffer (Promega), $100 \mathrm{ng}$ of each primer, $50 \mu \mathrm{M}$ of dCTP, $50 \mu \mathrm{M}$ of dGTP, $50 \mu \mathrm{M}$ of dTTP, $25 \mu \mathrm{M}$ of dATP, $12.5 \mu \mathrm{M}$ of $\left(\alpha-{ }^{35} \mathrm{~S}\right)$-dATP $(1,000 \mathrm{mCi} / \mathrm{mmol}$, Amersham) and 1.5 units of Taq polymerase (Promega). All SOD1 gene exons were amplified using thirty cycles of amplification: $30 \mathrm{~s}$ at $94^{\circ} \mathrm{C}, 30 \mathrm{~s}$ at $59^{\circ} \mathrm{C}\left(62^{\circ} \mathrm{C}\right.$ for exon 2) and $45 \mathrm{~s}$ at $72^{\circ} \mathrm{C}$ followed by a 5 -min extension at $72^{\circ} \mathrm{C}$.

The single-strand conformational polymorphism (SSCP) analysis ${ }^{15}$ was performed as described by Michaud et al. ${ }^{16}$ except for using an acrylamide concentration of $8 \%$ in the gels. In order to maximize the mutation detection, we also used the $0.5 \mathrm{X}$ Hydrolink MDE gel supplemented with or without $5 \%$ glycerol. Electrophoretic migration at $6 \mathrm{~V}$ and autoradiology were performed for 16 and 18 hours, respectively. Any difference in migration between patient and control samples was noted as positive. To confirm the SSCP results, symmetric direct sequencing method ${ }^{17,18}$ using modified T7 polymerase (sequenase, Amersham) was used as described by Brody et al..$^{19}$ All exons were sequenced at least once on each strand.

\section{Results}

In our hands the new oligonucleotide primers designed to amplify exons 1-3 (Table 1) gave clearer and more intense bands on SSCP than those described in reference 14 . Genomic DNA from 70 unrelated FALS affected patients and from 26 normal controls were screened for mutations in SOD1 gene in all 5 exons using primers from the flanking intron sequences. PCR-SSCP analysis of all DNA samples showed variant bands in 10 unrelated families (14.3\%). We had previously screened 300 controls for mutations in these exons; none were found.

Direct sequencing of PCR-amplified DNA from the 10 FALS individuals with SSCP variants confirmed the presence of mutations in all cases. We identified 6 new mutations of which 5 were missense nucleotide substitutions and one 3 bp deletion in intron 4 (Table 2). Two other known mutations were found in four patients (Asp90Ala and llel13Thr). ${ }^{5,20}$ All affected patients with the SOD1 mutations are heterozygotes except for Leu84Phe and Asp90Ala amino acid substitutions where patients were homozygous. The $3 \mathrm{bp}$ (CTT) deletion detected in intron 4 is $30 \mathrm{bp}$ downstream of exon-intron splice junction.

\section{DisCUSSION}

All 5 exons of the SOD1 gene from 70 unrelated FALS affected patients were screened for mutations using SSCP. Using our SSCP protocol, which involves testing of DNA fragments smaller than $300 \mathrm{bp}$ using many different gel conditions, we expect to have

Table 1: Amplified DNA length, annealing temperature and oligonucleotide primer sequences for PCR amplification of Human SOD1 gene exons.

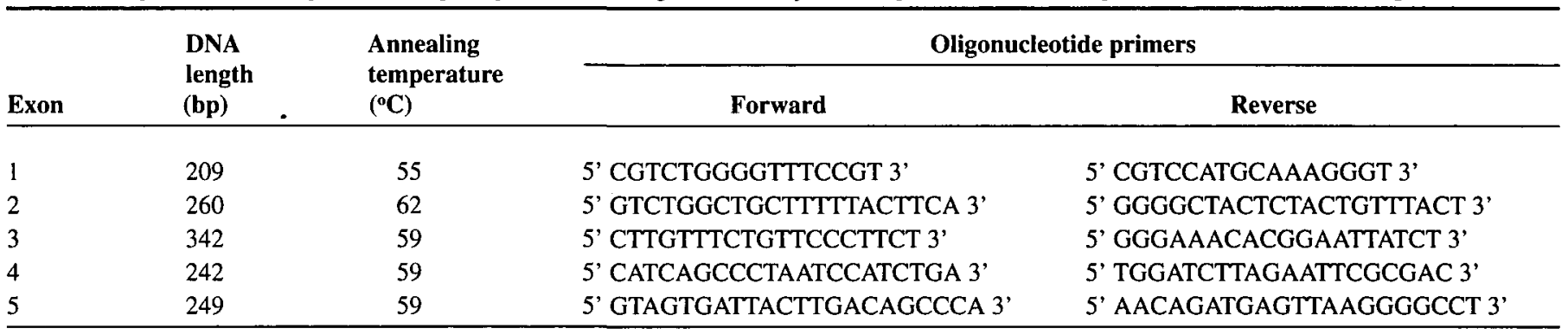

Table 2: Novel SOD1 mutations in familial amyotrophic lateral sclerosis.

\begin{tabular}{|c|c|c|c|c|c|}
\hline & $\begin{array}{l}\text { Codon } \\
\text { changes }\end{array}$ & $\begin{array}{l}\text { Restriction site } \\
\text { changes }\end{array}$ & $\begin{array}{l}\text { Amino acid } \\
\text { substitution }\end{array}$ & Structural location ${ }^{\mathrm{a}}$ & $\begin{array}{l}\text { Mammalian } \\
\text { amino acid identity }\end{array}$ \\
\hline \multirow[t]{4}{*}{ Exon 2} & GAG6 GGG & $-\mathrm{Taq}$ I & Glu 21 Gly & $\beta$ strand & $8 / 8$ \\
\hline & CTG6 CGG & & Leu 38 Arg & Greek key & $8 / 8$ \\
\hline & GAG6 AAG & $-B s p H ~ I ~$ & Glu 49 Lys & $\mathrm{Cu}^{2+}$ binding site & $3 / 8$ \\
\hline & & -Nla III & & or dimer contact & \\
\hline \multirow[t]{3}{*}{ Exon 3} & CTA6 CGA & +Taq I, & Leu $67 \mathrm{Arg}$ & Active site loop & $6 / 8$ \\
\hline & & +Mbo I & & & \\
\hline & & + Sau3A I & & & \\
\hline Exon 4 & TTG6 TTC & & Leu 84 Phe & Zinc binding site & $8 / 8$ \\
\hline Intron 4 & AAAACT 1 & CTAA6 AAAAC & & & \\
\hline
\end{tabular}




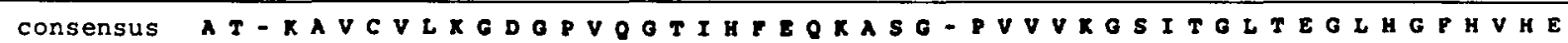

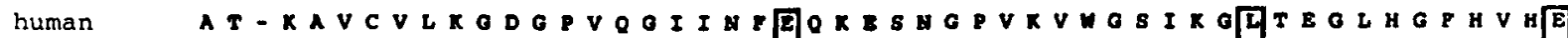

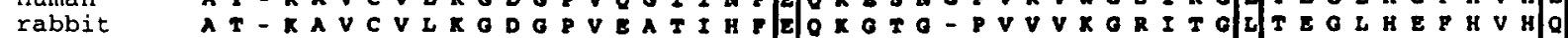

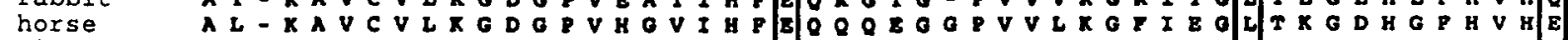

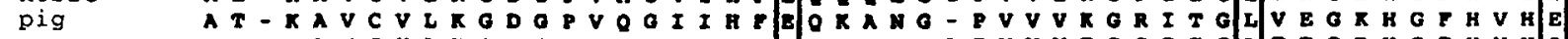

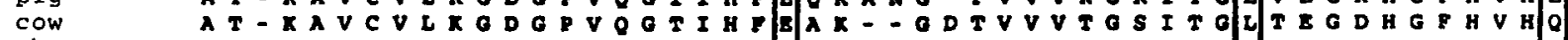

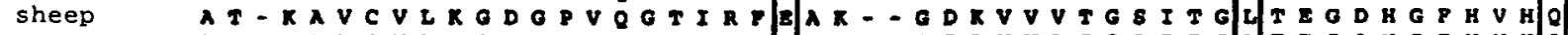

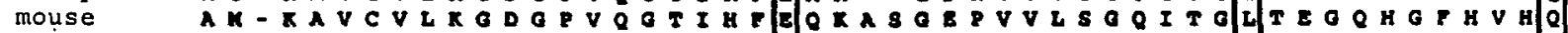

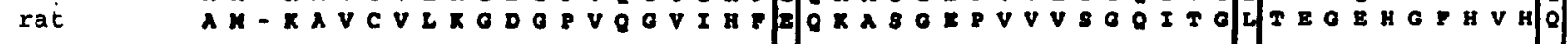

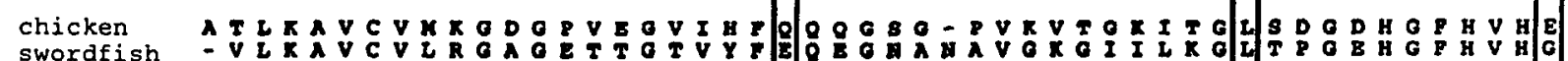

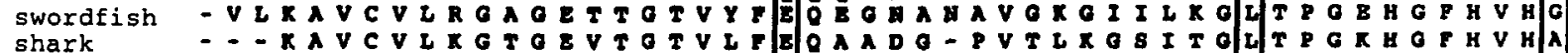

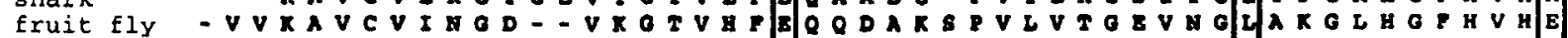

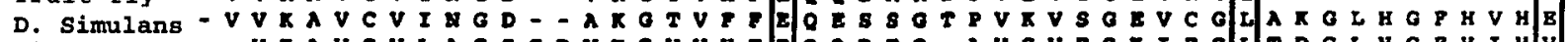

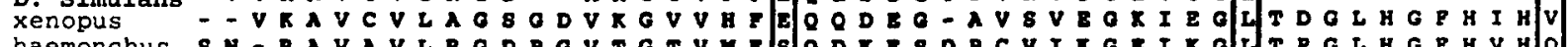

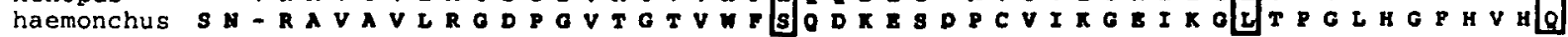

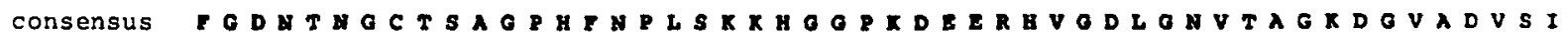
98

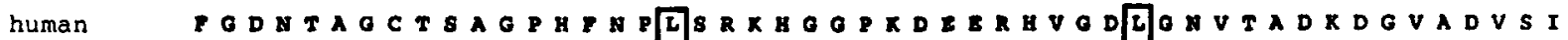

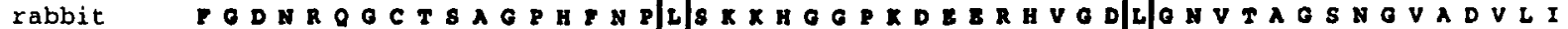

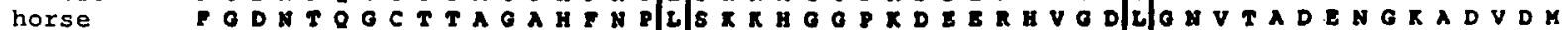
pig

cow

mouse

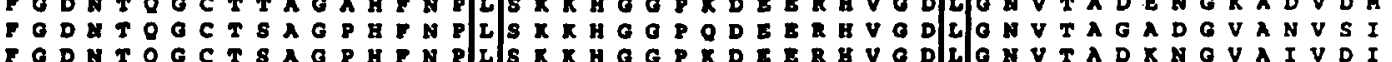
F G D N T O G C T E A G P H F N P L

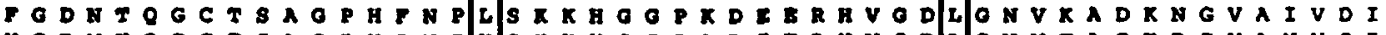
rat

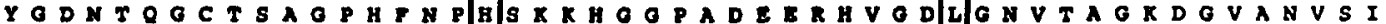

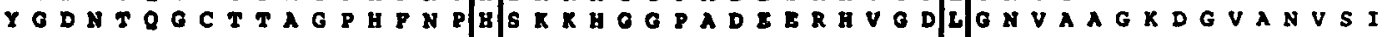

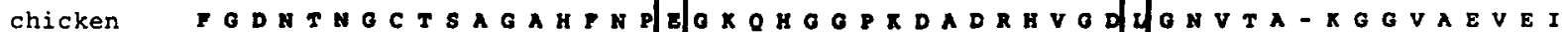

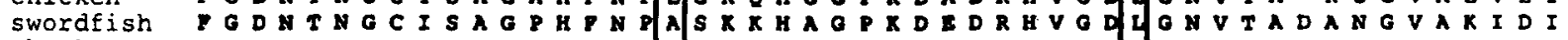

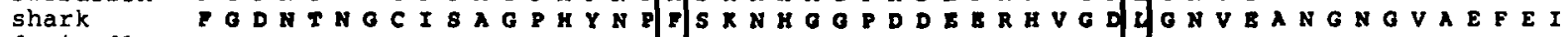

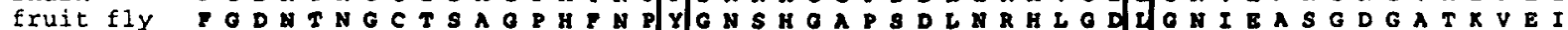

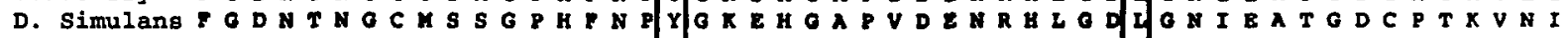

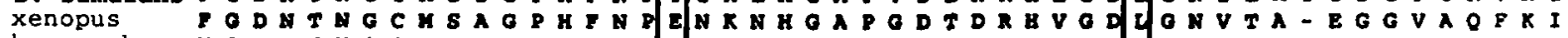

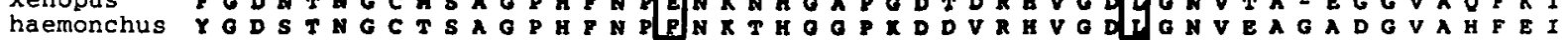

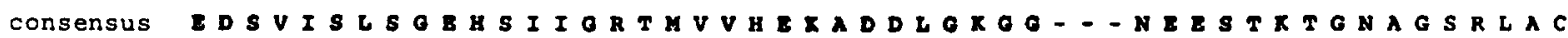

human

rabbit

horse

pig

cow

sheep

mouse

rat

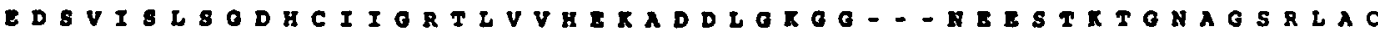

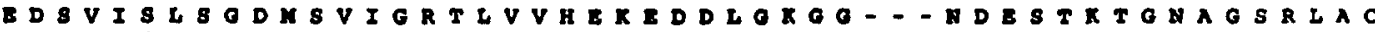

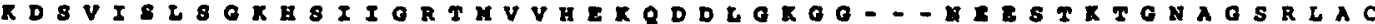

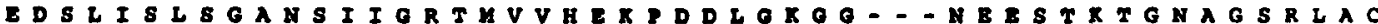

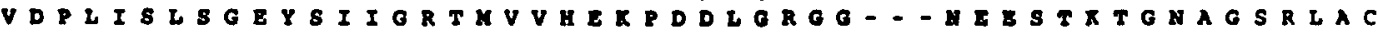

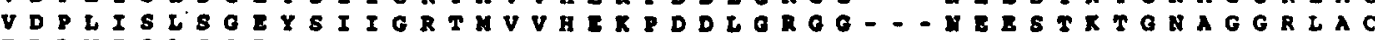

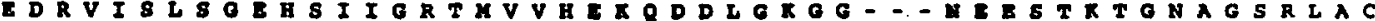

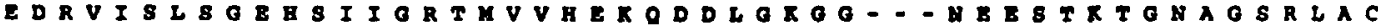

chicken swordfish shark

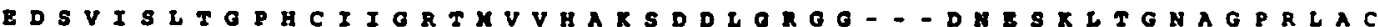

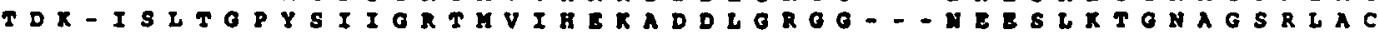

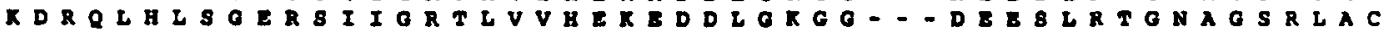

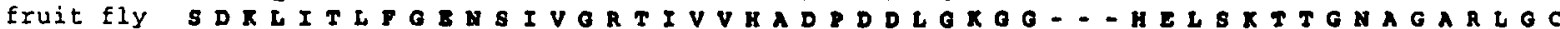

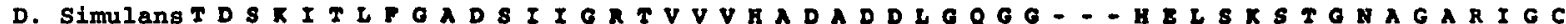

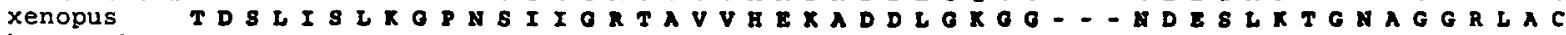

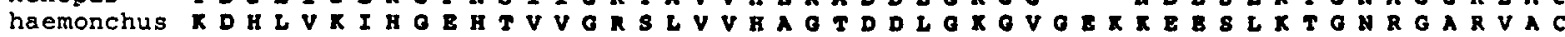

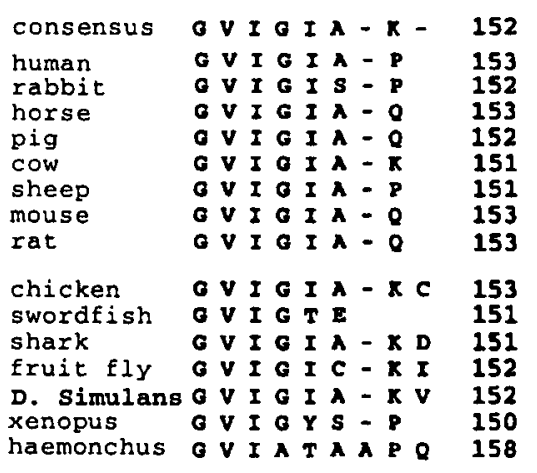

Figure: Amino acid sequence comparison of the SOD1 protein in 15 different species.

All SODI protein sequences were obtained from GenBank. The protein sequence comparison was performed using DNASTAR package software (DNASTAR Inc., Wisconsin). The amino acids representing the novel mutations reported in this article are boxed. Hyphens indicate amino acid deletions. 
detected over $90 \%$ of all mutations, suggesting that few, if any, were missed in our screen. Therefore, $14.3 \%$ of our FALS families showed a defect in the SOD1 gene, confirming the relatively low prevalence of SOD1 mutations found in previous studies. ${ }^{8,22}$

We found three new mutations in exon 2 replacing Glu 21 by Gly, Leu 38 by Arg and Glu 49 by Lys. At the position 21, a Glu21Lys mutation was previously reported in one sporadic case of ALS. ${ }^{23}$ The SOD1 protein of all compared species in the Figure contain the Glu 21, except chicken and nematodes, showing that this amino acid is highly conserved. Based on the bovine and yeast crystallographic SOD1 protein structure ${ }^{21}$ Glu 21 is part of a $\beta$ strand. Thus the Glu21Gly mutation may destabilize the SOD1 structure. As predicted for Leu38Val mutation, ${ }^{21}$ Leu38Arg would be expected to destabilize protein folding by altering a Greek Key. The bovine and yeast crystallographic SOD1 protein structure ${ }^{21}$ show that Glu 49 is involved in dimer contact or $\mathrm{Cu}^{2+}$ binding. While the amino acid Glu 49 is not highly conserved between species, this substitution constitutes a significant amino acid change from a negatively charged (Glu) to a positively charged (Lys) amino acid.

In exon 4 we found another novel mutation, Leu84Phe, and two previously published mutations Asp90Ala and Ilel13Thr in six unrelated families. One of our families carrying an Asp90Ala mutation contains two affected patients and two normal individuals who are homozygotes and heterozygotes, respectively for the mutation (B. Moulard and Y. Boukaftane, in preparation). This finding supports a recessive inheritance mechanism for the Asp90Ala mutation. ${ }^{5,9}$ The Leu 84 amino acid is conserved in all known mammalian SODl genes (Figure), and it is a part of fourteen conserved amino acids region which would have an important role in SOD1 function. Surprisingly, the woman patient carrying the Leu84Phe mutation is homozygote. She died at the age of 43 years, 3 years after the onset of the disease. She has a 48 year-old normal sister found also to be homozygous for the same mutation.

We also found a deletion of three nucleotides 30 bp downstream of the exon-intron splice junction in intron 4 . The consequence of this mutation is unknown. The patient and his parents have died and no cell line is available to test for splicing errors or other biological effects. However, the mutation is not seen in 600 control chromosomes.

We found one kindred showing a missense mutation (CTA to CGA; Leu67Arg) in exon 3 which encodes the Zn-binding loop of the active site. This mutation replaces a predicted Leu at position 67 by an Arg, introducing a voluminous amino acid with a positive charge, which constitutes a major structural change. The $\mathrm{Zn}^{2+}$ ion is known to be a potential neurotoxin. ${ }^{24-26}$ Therefore, the alteration of SOD1 role in the binding of $\mathrm{Zn}^{2+}$ may affect its homeostasis leading to neurodegeneration. We have found two different mutations involving the $\mathrm{Zn}^{2+}$ binding site (Leu67Arg and Leu84Phe), in two unrelated FALS patients suggesting a possible role of $\mathrm{Zn}^{2+}$ ions in the development of ALS.

This study increases the number of known mutations causing FALS to 55 involving 37 different codons. The fact that we have found 5 new missense mutations suggest there are other as yet undiscovered SODI mutations in FALS. This represents a surprisingly large number of gain of function mutations for such a small protein.

\section{Abbreviations}

ALS, Amyotrophic lateral sclerosis; FALS, familial ALS; SOD 1, Cu/Zn superoxide dismutase I; SALS, sporadic ALS; SSCP, single strand conformational polymorphism.

\section{ACKNOWLEDGEMENTS}

We thank members of FALS kindreds for their cooperation G.A.R. is supported by the Medical Research Council of Canada. The work was supported by the Muscular Dystrophy Association (U.S.A.), the ALS Association, the Association Française contre le Myopathie and the Association pour la recherche sur la sclérose laterale amyotrophique.

\section{REFERENCES}

1. Tandan R, Bradley WG. Amyotrophic lateral sclerosis: Part 1. Clinical features, pathology, and ethical issues in management. Ann Neurol 1985; 18: 271-280.

2 Tandan R, Bradley WG. Amyotrophic lateral sclerosis: Part 2. Etiopathogenesis. Ann Neurol 1985; 18: 419-431.

3. Mulder DS, Kurland LT, Offord KP, Beard CM. Familial adult motor neuron disease: amyotrophic lateral sclerosis. Neurology 1986; 36: $511-517$

4. Hentati $A$, et al. Linkage of recessive familial amyotrophic lateral sclerosis to chromosome 2q33-q35. Nat Genet 1994; 7: 425-428.

5. Andersen PM, et al. Amyotrophic lateral sclerosis associated with homozygosity for an Asp90Ala mutation in $\mathrm{CuZn}$-superoxide dismutase. Nat Genet 1995; 10: 61-66.

6. Rosen DR, et al. A frequent ala 4 to val superoxide dismutase-1 mutation is associated with a rapidly progressive familial amyotrophic lateral sclerosis. Hum Mol Genet 1994; 3: 981-987.

7. Siddique T, et al. Linkage of a gene causing familial amyotrophic lateral sclerosis to chromosome 21 and evidence of genetic-locus heterogeneity. N Engl J Med 1991; 324: 1381-1384.

8. Siddique T, Deng HX. Genetics of amyotrophic lateral sclerosis. Hum Mol Genet 1996: 1465-1470.

9. Andersen PM, et al. Autosomal recessive adult-onset amyotrophic lateral sclerosis associated with homozygosity for Asp90ala CuZnsuperoxide dismutase mutation. A clinical and genealogical study of 36 patients. Brain 1996; 119: 1153-1172.

10. Gurney ME, et al. Motor neuron degeneration in mice that express a human $\mathrm{Cu}, \mathrm{Zn}$ superoxide dismutase mutation. Science 1994; 264 : $1772-1775$.

11. Cleveland DW, et al. Mechanisms of selective motor neuron death in transgenic mouse models of motor neuron disease. Neurology 1996; 47: S54-S61; discussion S61-S62.

12. Kostic V, et al. Midbrain dopaminergic neuronal degeneration in a transgenic mouse model of familial amyotrophic lateral sclerosis. Ann Neurol 1997; 41: 497-504.

13. Brooks BR,. El Escorial World Federation of Neurology criteria for the diagnosis of amyotrophic lateral sclerosis. Subcommittee on Motor Neuron Diseases/Amyotrophic Lateral Sclerosis of the World Federation of Neurology Research Group on Neuromuscular Diseases and the El Escorial "Clinical limits of amyotrophic lateral sclerosis" workshop contributors. J Neurol Sci 1994; 124: S96S107.

14. Yulug IG, Katsanis N, de Belleroche J, Collinge J, Fisher EM. An improved protocol for the analysis of SODI gene mutations, and a new mutation in exon 4. Hum Mol Genet 1995; 4: 1101-1104.

15. Orita M, Iwahana H, Kanazawa H, Hayashi K, Sekiya T. Detection of polymorphisms of human DNA by gel electrophoresis of singlestrand conformation polymorphisms. Proc Natl Acad Sci USA 1989; 86: 2766-2770.

16. Michaud J, et al. Strand-separating conformational polymorphism analysis: efficacy of detection of point mutations in the human ormithine delta-aminotransferase gene. Genomics 1992; 13: 389-394.

17. Tahara T, Kraus JP, Rosenberg LE. Direct DNA sequencing of PCR amplified genomic DNA by the Maxam-Gilbert method. Biotechniques. 1990; 8: 366-368 
18. Kusukawa N, Uemori T, Asada K, Kato I. Rapid and reliable protocol for direct sequencing of material amplified by the polymerase chain reaction. Biotechniques 1990; 9: 66-72.

19. Brody LC, et al. Ornithine delta-aminotransferase mutations in gyrate atrophy. Allelic heterogeneity and functional consequences. J Biol Chem 1992; 267: 3302-3307.

20. Rosen DR, et al. Mutations in $\mathrm{Cu} / \mathrm{Zn}$ superoxide dismutase gene are associated with familial amyotrophic lateral sclerosis. Nature 1993; 362: 59-62.

21. Deng HX, et al. Amyotrophic lateral sclerosis and structural defects in $\mathrm{Cu}, \mathrm{Zn}$ superoxide dismutase. Science 1993; 261: 1047-1051.

22. Pramatarova $\mathrm{A}$, et al. Identification of new mutations in the $\mathrm{Cu} / \mathrm{Zn}$ superoxide dismutase gene of patients with familial amyotrophic lateral sclerosis. Am J Hum Genet 1995; 56: 592-596.
23. Jones CT, Swingler RJ, Brock DJ. Identification of a novel SODI mutation in an apparently sporadic amyotrophic lateral sclerosis patient and the detection of Ilel13Thr in three others. Hum Mol Genet 1994; 3: 649-650.

24. Ebadi M, Murrin LC, Pfeiffer RF. Hippocampal zinc thionein and pyridoxal phosphate modulate synaptic functions. Ann NY Acad Sci. 1990; 585: 189-201.

25. Choi DW, Yokayama M, Koh J. Zinc neurotoxicity in cortical cell culture. Neuroscience 1988; 24: 67-79.

26. Duncan MW, Marini AM, Watters R, Kopin IJ, Markey SP. Zinc, a neurotoxin to cultured neurons, contaminates cycad flour prepared by traditional guamanian methods. J Neurosci 1992; 12: 1523-1537. 